\title{
RELATIONSHIP MANAGEMENT IN ENTERPRISE NETWORKS
}

\author{
Arian Zwegers, Herbert Wubben \\ Baan,azwegers@baan.com,hwubben@baan.com \\ Ingo Hartel \\ Swiss Federal Institute of Technology Zurich \\ Center for Enterprise Sciences (ETHZ-BWI), Ingo.Hartel@ethz.ch
}

\begin{abstract}
Enterprises cooperate more extensively with other enterprises in various forms. To enable the cooperation of multiple organizations in supply chains or virtual enterprises, configuration and set-up tools need to define the relations between partnering enterprises. In the one-of-a-kind industry, enterprises collaborate within a Virtual Enterprise (VE). For the definition of relationships among partners in a VE, standard project management 'tools' can be used. EXtended Relationship Management (XRM) services define the relationships among partners in a VE. These services need to support a network view, viral effects, many-to-many relations, and 'configuration' of the integration infrastructure.
\end{abstract}

\section{INTRODUCTION}

One of the trends in the global market is the increasing cooperation among enterprises during the entire product life cycle. This is related to business drivers, such as the need for cost reduction, flexibility, focus on core competencies, and so on. The result is anything from a rather stable alliance between partners as in a supply chain to a more transitory cooperation as in a virtual enterprise.

To enable the cooperation of multiple organizations in supply chains or virtual enterprises, the relations between these partners need to be defined. Configuration and set-up tools are needed to define inter-enterprise relationships, in addition to applications for monitoring, management, and optimization of inter-enterprise business processes. Before processes within a supply chain or virtual enterprise can be executed, the relations between the various partners have to be defined by means of tools for the set-up of these cooperation forms. These so-called eXtended Relationship Management (XRM) services can be used to configure a whole supply chain or virtual enterprise (Radjou et al., 2001; Forrester, 2002)*. Changing

\footnotetext{
' Please note that this paper adopts a slightly different interpretation of the term 'XRM' than Forrester in (Radjou et al., 2001). According to Forrester's definition, XRM applications manage, monitor, and/or optimize inter-enterprise business processes. Here, we restrict ourselves to the services that allow an enterprise to define relations between enterprises. In Forrester's definition, this is only part of XRM applications. This functionality is in fact quite interesting for all collaborative applications, and should be made available to these applications as specialized services.
} 
configurations of partners in a virtual enterprise necessitate dynamic configurations of both inter-enterprise business processes and the integrations with partners' enterprise applications. Both should be easily modified. XRM tools aim to provide this easy and effective reconfiguration of cooperating partners.

The objective of this paper is to define how relationship management services should support the set-up and reconfiguration of a virtual enterprise out of an enterprise network. The focus is on the decomposition of an inter-enterprise project in order to obtain a more accurate picture of the distribution of work. Only then, it will be clear with what partners enterprises share specifications, on what basis they report progress, when they can start certain parts of the work, and so on. Irrespective of collaborative (project management) applications, the basis of collaboration is found in such a "cooperation structure".

The next section provides some background about 'collaborative commerce', virtual enterprises, and collaborative project management. They are respectively the business model, the organizational structure, and one of the most obvious applications in which XRM plays a role. In section 3, the characteristics of XRM services are defined, and its place in an integration infrastructure is outlined. A case of a virtual enterprise in practice is presented in section 4 . The paper gives a first glance of how the relations between the partners in that virtual enterprise can be modeled. A discussion closes this paper. The research has been carried out as part of the IMS project 'GLOBEMEN - Global Engineering and Manufacturing in Enterprise Networks' (IMS 99004, EC project IST-1999-60002).

\section{BACKGROUND}

\subsection{Trend Toward "Collaborative Commerce"}

Nowadays, three major movements put additional requirements to enterprises: globalization, outsourcing, and customization. Organizations expand their scope to become really global, and differentiate their patterns of cooperation to encompass collaborative activities. Outsourcing and a focus on core competencies requires better collaboration, synchronization of processes, and appropriate handling of time and distance constraints. Customization demands make-to-order manufacturing, better demand visibility, and more flexibility in general in order to execute faster and more efficiently. Closer collaboration with partners is required by globalization, outsourcing, and customization.

However, the trend towards closer collaboration is hindered by a number of factors. Current applications focus on single-tier environments, and provide limited support for complex partner relationships. Popular solutions which are available in the market today, such as Supply Chain Management applications, typically address cooperation within 'paired relationships'. The latter means that companies are inclined to optimize the relationships with their closest suppliers and customers in a one-to-one fashion. Only the cooperation between an enterprise and its closest suppliers or customers is considered. The supplier's suppliers and the customer's customers are not taken into consideration. Although the logistics management of an enterprise towards its direct partners might be optimized, the overall supply chain is far from optimal. 
Nevertheless, it is apparent that enterprises will have to adopt approaches such as "collaborative commerce" (or "c-commerce") to remain competitive in most industry segments (Forrester, 2002; Gartner, 2002). Gartner defines c-commerce as follows:

" $\mathrm{C}$-commerce is the collaborative, electronically enabled business interaction among an enterprise's internal personnel, business partners, and customers throughout a trading community. This trading community can be an industry, industry segment, supply chain or supply chain segment." (Gartner, 2002)*

Perhaps the most essential element of c-commerce is the extension of an enterprise's knowledge assets to include those outside the enterprise. When intellectual capital is leveraged across enterprises, the benefits of c-commerce can be realized. Sharing intellectual capital and combining core competencies with partners are the major ingredients of collaboration.

C-commerce should be considered as a business model rather than a solution that can be offered by vendors. It benefits an enterprise by extending the enterprise's visibility and cooperation throughout the value chain, thereby contributing to the realization of virtual enterprises.

\subsection{Virtual Enterprises}

Virtual Enterprises (VEs) are examples of implementations of the c-commerce business model. They are 'set up' from Enterprise Networks (see Figure 1). Such a network is a cooperative alliance of enterprises established to jointly exploit business opportunities through setting up virtual enterprises. The main purpose of a network is to prepare and manage the life cycle of VEs. It establishes mutual agreements among its members on issues such as common standards, procedures, intellectual property rights, and ICT, so that these time-consuming preparations can be significantly shortened when a customer request arises, and a VE is put in place. The network should be seen as a potential from which different VEs can be established in order to satisfy diverse customer demands. The network will seek out and await customer demands, and when a specific customer demand is identified the business potential is realized by forming a VE. Accordingly, compared to a virtual enterprise, a network can be perceived as a relatively long-term cooperation since it typically sets up multiple VEs. Conversely, the VEs have a more temporary nature.

A network is principally created based on core competencies and capabilities assigned from different cooperating enterprises. The network can therefore be characterized as a portfolio of core competencies that are available to realize VEs and products. This competence portfolio is dynamic in the sense that competencies can leave and join the network. In addition, a network can be characterized as a product-oriented network focusing on the strategically important, value adding partner competencies in the potential VEs, while typically excluding off-the-shelf suppliers (Van den Berg et al., 2000).

A Virtual Enterprise is a temporary alliance of enterprises that come together to share skills or core competencies and resources in order to better respond to a business opportunity, and whose cooperation is supported by ICT (derived from

\footnotetext{
* See Eschenbächer and Zwegers (2002) for a discussion on different interpretations of the term 'ccommerce'.
} 


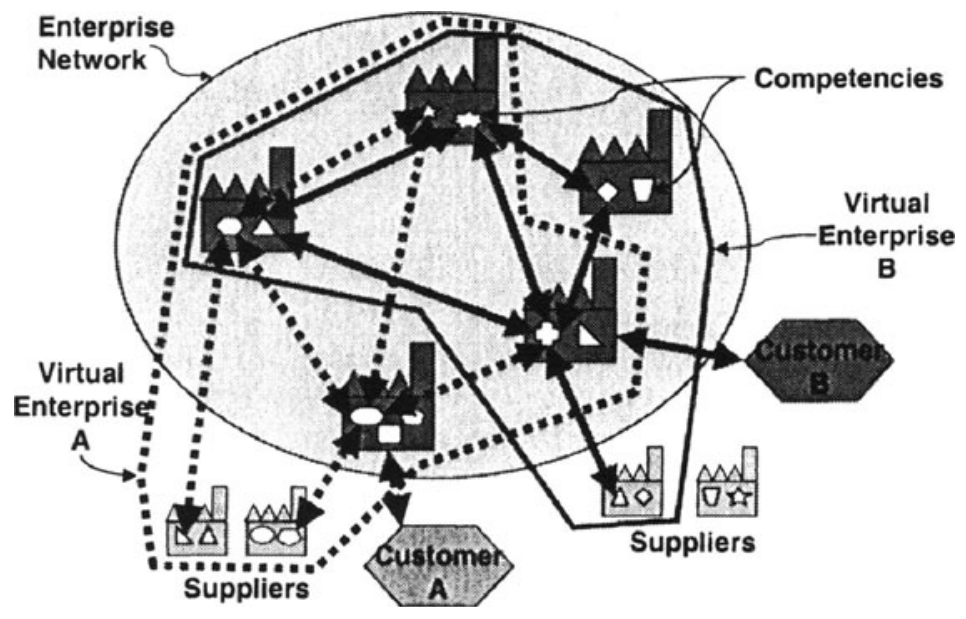

Figure 1 - Enterprise Network and Virtual Enterprises

(Camarinha-Matos, 2000)). Formation of the VE materializes through configuration of the core competencies and capabilities available in the network and possibly through inclusion of additional, required competencies provided by non-network participants, cf. Figure 1. Though being comprised by competencies from various partners, the VE performs as one, unified, and attuned enterprise. Hence its virtual nature. Accordingly, the business processes are not carried out by a single enterprise, but every enterprise is a node in the VE that adds some value to the product chain.

Please note that in the set-up of a VE from an enterprise network, the rather 'loose' relations that exist among enterprises in a network become 'solid' in a VE. In a network, there is no notion of a specific product or project. On the other hand, the VE is set up with a specific purpose in mind, i.e. a specific project delivering a specific product for a known customer. The configuration of the VE comprises the definition of the tasks/roles of individual enterprises and the relations between them. Concrete agreements are made regarding deliverables, schedules, payments, and so on, which are detailed in contracts and project plans.

\subsection{Collaborative Project Management}

This paper focuses on the one-of-a-kind industry. In this industry, enterprises participate in complex projects with significant durations and resource usages. These projects are split into many activities, deliverables, and milestones. They take place in a distributed environment within a temporary, product driven, inter-enterprise structure (the virtual enterprise) and usually with geographically distributed sites (plants, construction sites, and so on).

Due to these difficulties, collaborating enterprises are looking for more reliable project plans with a shared model of project activities and requirements. That way, they can monitor the project through on-line access to activity progress, with realtime notification of events and 'alert' conditions and impact evaluation for deviations based on changes of downstream activities. This will enable enterprises to diminish risks, since unexpected events or plan deviations are reduced and there is 
clear visibility between all activities. In addition, it will allow enterprises obtaining a higher level of flexibility and efficiency, responding faster to customer change requests, exploiting partner competencies from the network potential in a better way, and accelerating and controlling the flow of information during the project life cycle.

\section{EXTENDED RELATIONSHIP MANAGEMENT (XRM)}

\subsection{Definition of Relationships Among Partners in a VE}

For the definition of relationships among partners in a VE, rather standard project management 'tools' should be used. These 'tools' are:

- Work Breakdown Structure, i.e. a deliverable-oriented grouping of project elements that organizes and defines the total work scope of the project. Each descending level represents an increasingly detailed definition of the project work (PMBOK, 2000).

- Organization Breakdown Structure, i.e. a depiction of the project organization in which work packages are related to organizational units (PMBOK, 2000).

- Project Network Diagram, i.e. a schematic display of the logical relationships of project activities, which is always drawn from left to right to reflect project chronology. It is often referred to as a PERT chart (PMBOK, 2000).

- Bill of Material, i.e. a diagram presenting a hierarchical view of the physical assemblies, subassemblies, and components needed to fabricate a manufactured product. It contains the products that are required and must be produced, installed, assembled, and described in a hierarchical way.

The key point is the combination of these structures. A Work Breakdown Structure can be decomposed into more detailed activity structures, which eventually drill down to normal Bills of Material. The components in such a Bill of Material are provided by suppliers according to normal supply chain relationships. Tools are available to support these supply chain relationships. In addition, some project management tools support multi-enterprise Work Breakdown Structures. However, the combination is still unique.

\subsection{Characteristics of XRM Services}

XRM services defining the relationships among partners in a virtual enterprise need to exhibit certain characteristics, namely they need to support a network view, viral effects, many-to-many relations, and 'configuration' of the integration infrastructure.

XRM services need to provide a network point of view. Enterprise applications such as ERP and SCM typically consider an enterprise or an enterprise plus its direct suppliers and customers. They adopt an enterprise view and an 'enterprise + tier 1 ' view respectively. However, XRM must go beyond the paired relationships and must create transparency across multi-tier boundaries. They take the whole supply chain or virtual enterprise and thereby supplier's suppliers and the customer's 
customers into consideration. In addition, each individual virtual enterprise member has visibility into its position in the virtual enterprise, possibly restricted to one tier only, depending on the authorities it was given.

XRM services need to support viral effects, so that partners can introduce their own suppliers and customers. While XRM services are sponsored and hosted by a single firm (usually a main contractor or dedicated service provider), partners can pay to extend the services to their other partners and customers. The whole virtual enterprise can be set up more efficiently this way (Radjou et al., 2001).

XRM services need to support many-to-many relationships. Especially in supply chains with rather standard products, a component manufacturer supplying to multiple OEMs, wants to give access to its production schedules to all OEMs. However, a building contractor hosting XRM services and collaborative project management applications does not want its subcontracted engineering firms to set up virtual enterprises with other, competing building contractors.

XRM services need to 'configure' the integration infrastructure, i.e. regardless of where a partner is located in the virtual enterprise, it will be able to set security, encryption, alerts, permission and data access to enterprises further up or complementary in the value chain. This way, information flows can be orchestrated.

\subsection{XRM in the Integration Infrastructure}

$\mathrm{XRM}$ is seen as one of the services provided by an integration infrastructure. Collaborative applications are positioned on top of the infrastructure. Van Busschbach et al. (2002) describe the capability stack of services needed for the complete integration backbone. It consists of four functional layers (from bottom to top):

- Connectivity Layer, linking applications in different programming languages, databases, middleware, protocols, and other technologies.

- Transformation Layer, reconciling differences in data and functions on a functional level.

- Routing Layer, providing dynamic behavior based on the contents of a message, to be configured by a business analyst.

- Process Management Layer, allowing the end user to dynamically trigger, execute and monitor business processes.

XRM services reside in the Process Management Layer. They use "yellow pages" about the enterprise network, which includes for example information about competences of potential partners. In addition, documents such as general agreements, procedures, and so on, can be stored for later use during the setup and operation of a VE. XRM models enterprises and their relationships in one or more projects based on Work Breakdown Structures, Activity Structures, and Bills of Material. These models form the basis for monitoring and management of the business processes in virtual enterprises by collaborative project management applications. The business processes managed in the Process Management Layer dictate the flow of information between applications and other data sources. Perhaps the ultimate goal of this layer is to provide inter-enterprise workflow management services that support multiple dynamic workflows crossing organizational boundaries. 


\section{AN INDUSTRIAL CASE STUDY}

Within the context of IMS project 'GLOBEMEN', XRM services have been developed. Though these services do not entirely implement the ideas as presented above, the basic principles behind the XRM services and especially their characteristics are identical. The services have been developed with the following reasoning in mind: enterprises close contracts; contracts contain obligations; obligations are linked to deliverables; deliverables can be organized in a project; every deliverable is related to a matched deliverable if this deliverable is subcontracted; and every planned deliverable is related to an actual deliverable.

The case is that of a paper mill producer (PMP), its customer (C), and one of its subcontractors (SC). $\mathrm{C}$ is customer of PMP. Both enterprises agreed on the delivery of (a part of) a paper machine by PMP to $C$. As a customer, $C$ requests to be reported on the progress of the part of the paper machine that is developed by PMP.

PMP organizes the delivery of that paper machine as a project, and decomposes the paper machine in three parts (Conveyor, Wrapper, and Rolls) for internal project management and subcontracting of one part. The Rolls will be constructed by another company (SC) and it is agreed that SC will report progress on the total and on three deliverables/activities for the Rolls: design, build and installation. For all deliverables, progress is being registered on actual deliverables that realize planned deliverables. Figure 2 shows the accompanying 'cooperation structure'. Note that this picture seamlessly integrates a Work Breakdown Structure with a sales order for a deliverable and a purchase order with one deliverable and three sub-deliverables.

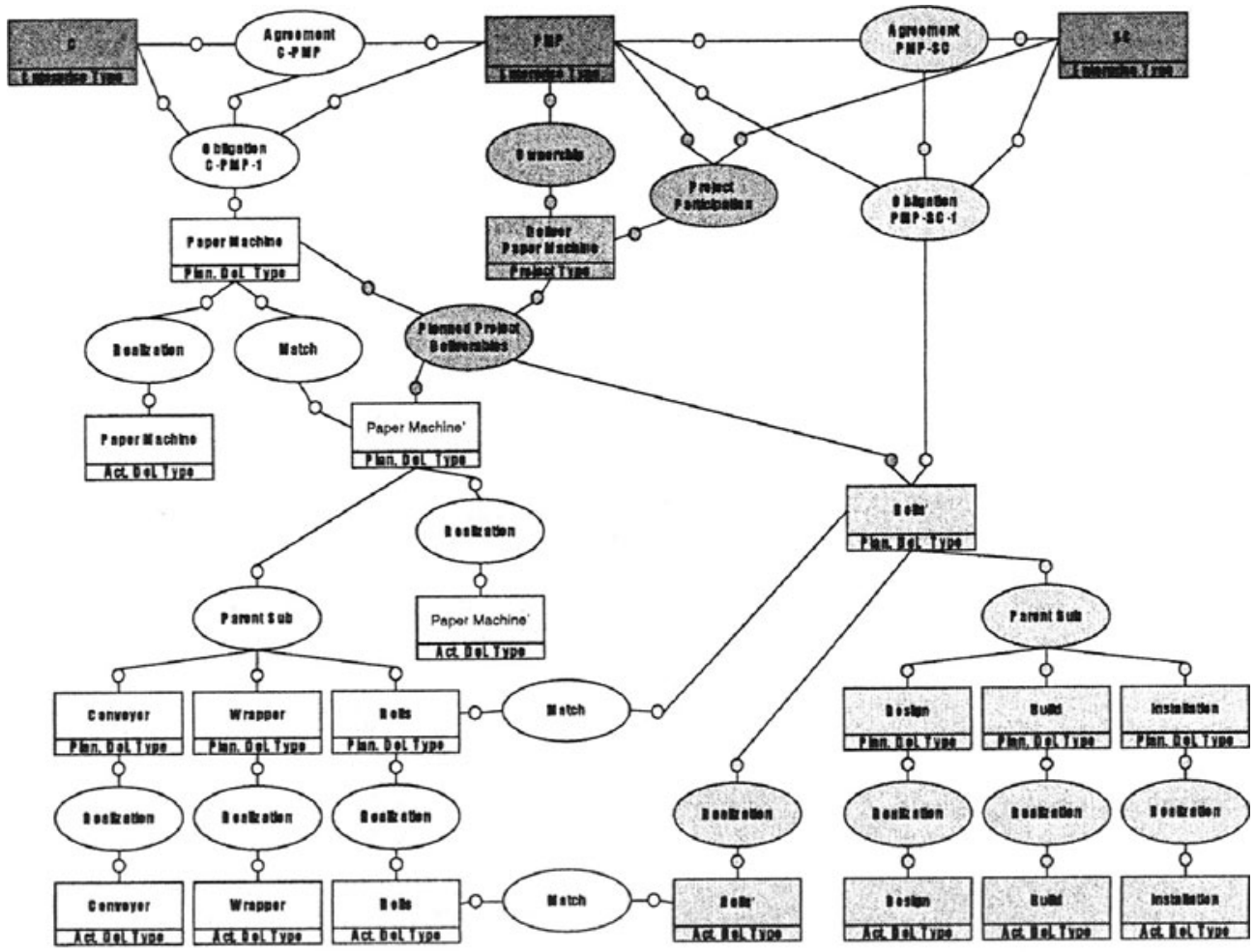

Figure 2 - Cooperation structure 
SC reports the progress on the deliverables Design, Build, and Installation, and Rolls'. These instances are also in the scope of PMP, since PMP and SC have agreed on the deliverables and their structure. Therefore, it is possible for PMP to track the progress. Note that SC does not (yet) organize the delivery of the Rolls as a project. $\mathrm{SC}$ could define the parts of Rolls which are subcontracted again, thanks to the viral capabilities of the XRM services."

PMP is able to track progress on a subcontracted part of the Paper Machine': Rolls'. PMP also tracks and reports progress on Paper Machine' and its subdeliverables internally, and is able to report progress on the Paper Machine to customer $\mathrm{C}$.

\section{DISCUSSION}

XRM services can be found in various forms in collaborative applications. After all, a cooperation can only be defined and detailed with XRM-like services. The cooperation structures and XRM characteristics mentioned in this paper are mostly based on experiences with collaborative project management applications in the oneof-a-kind industry. Other applications, e.g. focused on short-lived VEs such as virtual service enterprises, which fulfill services like maintenance, inspection or repair collaboratively, might need simpler cooperation structures (Hartel, 2001).

This paper presents the first results obtained with XRM services within the IMS project 'GLOBEMEN'. Further research will focus on the genericity of the identified structures within the one-of-a-kind industry and on the genericity of the characteristics in XRM services. A prototype of an integration infrastructure realizing the desired $\mathrm{XRM}$ characteristics is also planned.

\section{REFERENCES}

1. Berg R. van den, Hannus M, Pedersen JD, Tølle $M$, and Zwegers A. "Evaluation of state of the art technologies". Globemen EU (IST-1999-60002) deliverable D411, 2000.

2. Busschbach E van, Pieterse B, Zwegers A. "Support of Virtual Enterprises by an Integration Infrastructure". In Collaborative Business Ecosystems and Virtual Enterprises (L.M. CamarinhaMatos (ed.)), pp. 311-326. Kluwer, Boston, 2002.

3. Camarinha-Matos LM. "Trends in virtual enterprise infrastructures". In Proceedings of WCC2000/ITBM 2000 - IFIP World Computer Congress/International Conference on Information Technology for Business Management. Beijing, China, 21-25 Aug 2000.

4. Eschenbächer J, Zwegers A. "Collaboration in value creating networks: the concept of collaborative commerce". In Proceedings of APMS 2002, Eindhoven, Netherlands (to be published), 2002.

5. Forrester. Various documents on URL: http://www.forrester.com, 2002.

6. Gartner. Various documents on URL: http://www.gartner.com, 2002.

7. Hartel I, Burger G. "Virtual Service Enterprise - A Model for virtual collaboration in after-sales service in the one-of-a-kind industry" In Proceedings of the IMS Forum, Ascona, Switzerland, 2001.

8. PMBOK. A guide to the Project Management Body of Knowledge (PMBOK® guide). Project Management Institute, Newtown Square, 2000.

9. Radjou N, Orlov LM, Child M. "Apps For Dynamic Collaboration". The Forrester Report. Cambridge, MA: Forrester Research, 2001.

\footnotetext{
* The quotation mark is used to make a difference between two representations of the Rolls deliverable. The representation without quotation mark is the representation that both $\mathrm{C}$ and PMP agree on. The representation with quotation mark is the representation that both PMP and SC agree on.
} 